ISSN 0853-8697

\title{
DESAIN KONTROL PID DENGAN METODA TUNING DIRECT SYNTHESIS UNTUK PENGATURAN KECEPATAN MOTOR DC
}

\author{
R.B.Moch. Gozali \\ Program Studi Teknik Elektro, Universitas Jember \\ Tlp : 0331-332447 HP: 08155911990
}

\begin{abstract}
PID controller is a controller which commonly used in industrial world. The importance of PID controller design is the ability to determine controller parameter or tuning. In this research, Direct Synthesis tuning method will be discussed.

Generally, PLC is used as sequence regulator device. PLC also can be used as digital PID controller by using ASCII module (Omron) which has ability to adopt BASIC language programming. Direct Synthesis can be implemented by integrating PLC as PID controller with DC motor as a plant. Result shows that Direct Synthesis tuning method increase plant performance significantly.
\end{abstract}

Keywords : PID controller, tuning, PLC

\section{PENDAHULUAN}

Kontroler PID adalah kontroler berumpanbalik yang paling populer di dunia industri. Selama lebih dari 50 tahun, kontroler PID terbukti dapat memberikan performa kontrol yang baik meski mempunyai algoritma sederhana yang mudah dipahami [1]. Hal krusial dalam desain kontroler PID ialah tuning atau pemberian parameter $\mathrm{P}, \mathrm{I}$, dan $\mathrm{D}$ agar didapatkan respon sistem yang diinginkan.

Salah satu metoda yang muncul ialah tuning berdasar model plant, karena identifikasi plant bukan lagi hal yang sulit untuk dilakukan. Salah satu jenisnya ialah Direct Synthesis yang memerlukan model plant sebenarnya dan model plant yang diinginkan untuk mendapatkan parameter P, I, D dari kontroler [2].

Sementara itu, di dunia industri juga dikenal adanya Programmable Logic Controller (PLC) sebagai alat pengatur urutan proses secara digital. Namun sekarang ini PLC telah dapat juga menangani proses analog. PLC C200H OMRON mengadaptasi hal itu dengan munculnya special unit seperti Analog Input Unit, Analog Output Unit, PID Controller, ASCII Unit, dan lain - lain [3].

Karena itu, paper ini akan mengimplementasikan kontroler PID pada modul ASCII untuk mengatur kecepatan motor DC. Selain itu akan dilakukan penerapan metoda tuning Direct Synthesis pada kontroler PID. Sebagai catatan, tidak semua metoda tuning cocok digunakan untuk jenis-jenis plant tertentu. Misalnya: penggunaan metoda tuning Ziegler-Nichols untuk pengaturan posisi motor DC justru memberikan hasil yang mengecewakan saat kontroler PID diterapkan [4]. 


\section{LANDASAN TEORI}

\subsection{Kontroler PID [4]}

Kontroler adalah komponen yang berfungsi meminimasi sinyal kesalahan. Tipe kontroler yang paling populer ialah kontroler PID. Elemen-elemen kontroler $\mathrm{P}$, I dan D masingmasing secara keseluruhan bertujuan untuk mempercepat reaksi sebuah sistem, menghilangkan offset dan menghasilkan perubahan awal yang besar.

Persamaan kontroler PID dalam bentuk Laplace:

$$
M(s)=K_{c}\left(E(s)+\frac{1}{T_{1} s} E(s)+T_{D} s E(s)\right)
$$

\subsection{Tuning Kontroler dengan Model Plant Nyata [2]}

Aspek yang sangat penting dalam desain kontroler PID ialah penentuan parameter kontroler PID supaya sistem close loop memenuhi kriteria performansi yang diinginkan. Hal ini disebut juga dengan tuning kontroler.

Seiring dengan berkembangnya penelitian tentang identifikasi suatu sistem "black box", maka memperoleh transfer function atau karakteristik dari sistem tersebut bukanlah hal yang teramat sulit. Hal ini menyebabkan metoda tuning kontroler yang membutuhkan model plant sebenarnya juga dapat dilakukan dengan relative mudah, misalnya dengan metoda Direct Sinthesys.

Metoda ini terlebih dulu menentukan perilaku ouput yang diinginkan (reference) dengan membuat bentuk trayektorinya, dan model prosesnya (plant) digunakan untuk secara langsung mendapatkan persamaan kontroler yang sesuai.

Berikut ini penurunan rumusnya. Jika diketahui diagram blok dari suatu system ialah sebagai berikut.

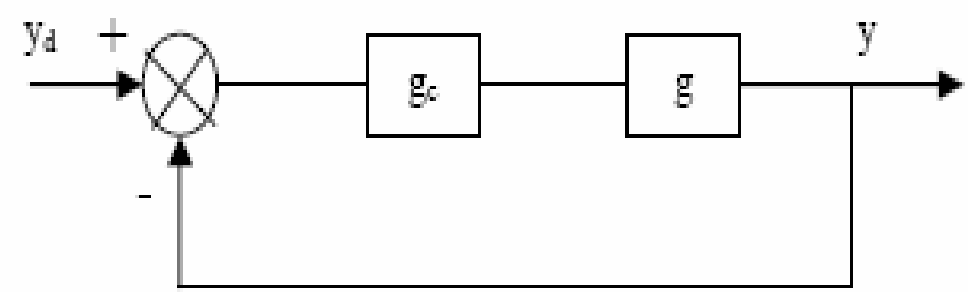

Gambar 1. Blok diagram dari sistem kontrol berumpan balik

Maka closed-loop transfer function ialah sebagai berikut :

$$
y(s)=\frac{g g_{c}}{1+g g_{c} h} y_{d}(s)
$$

Dan pendekatan yang diinginkan untuk mendapatkan setpoint yang baru dimodelkan

dengan trayektori yang diinginkan berikut : 


$$
\frac{y(s)}{y_{d}(s)}=q(s)=\frac{g g_{c}}{1+g g_{c} h}
$$

sehingga persamaan kontrolernya :

$$
g_{c}=\frac{1}{g}\left(\frac{q}{1-q}\right)
$$

Sesuai dengan transfer function plant motor DC yang telah didapatkan dan berbentuk First Order Plus Dead Time (FOPDT), yaitu:

$$
g(s)=\frac{K \cdot e^{-a s}}{\tau s+1}
$$

Dan dipilih reference trajectory:

$$
q(s)=\frac{e^{-a_{r} s}}{\tau_{r} s+1}
$$

Dengan memasukkan hasil Persamaan 5 dan Persamaan 6 pada Persamaan 4 maka didapat persamaan kontroler :

$$
g_{c}=\frac{(\tau s+1)}{K}\left(\frac{1}{\tau_{r} s+1-e^{-a s}}\right)
$$

Akhirnya didapatkan kontroler dalam bentuk persamaan, namun untuk merealisasikannya sangat sulit karena besaran tidak bisa diimplementasikan dalam komponen analog. Namun dengan adanya implementasi kontroler PID pada mikroprosesor dan komputer digital membuat besaran tersebut bisa diimplementasikan.

Melalui model dasar kontroler ini didapatkan beberapa macam nilai tuning PID yang berbeda-beda.

Dengan menggunakan pendekatan Pade orde 1 :

$$
e^{-a s} \approx \frac{1-\frac{\alpha}{2} s}{1+\frac{\alpha}{2} s}
$$

Pada Persamaan 7 , kontroler yang didapatkan menjadi

$$
g_{c}=\frac{\tau}{K\left(\tau_{r}+\alpha\right)}\left(1+\frac{1}{\tau s}\right)\left(\frac{1+\frac{\alpha}{2} s}{1+\tau^{*} s}\right)
$$

dengan $\tau^{*}$ adalah filter yang mempunyai persamaan sebagai berikut:

$$
\tau^{*}=\frac{\alpha \tau_{r}}{2\left(\alpha+\tau_{r}\right)}
$$


Persamaan 9 mempunyai struktur sesuai dengan struktur kontroler PID komersial. Maka

parameter kontroler PID komersial dapat dicari sebagai berikut :

$$
K_{c}=\frac{\tau}{K\left(\tau_{r}+a\right)} ; \tau_{l}=\tau ; \tau_{D}=\frac{\alpha}{2} ; \tau^{*}=\frac{\alpha}{2}\left(\frac{\tau_{r}}{\alpha+\tau_{r}}\right)
$$

Dengan kontroler yang sama, persamaan di atas dapat disusun kembali menjadi :

$$
g_{c}=\frac{\tau+\frac{\alpha}{2}}{K\left(\tau_{r}+\alpha\right)}\left[1+\frac{1}{\left(\tau+\frac{\alpha}{2}\right) s}+\left(\frac{\alpha \frac{\tau}{2}}{\tau+\frac{a}{2}}\right)\right]\left(\frac{1}{\tau^{*} s+1}\right)
$$

Maka parameter tuning dari kontroler PID ideal ialah :

$$
K_{c}=\frac{\tau+\frac{\alpha}{2}}{K\left(\tau_{r}+\alpha\right)} ; \tau_{l}=\tau+\frac{\alpha}{2} ; \tau_{d}=\frac{\frac{\alpha}{2} \tau}{\tau+\frac{\alpha}{2}} ; \tau^{*}=\frac{\alpha}{2}\left(\frac{\tau_{r}}{\alpha+\tau}\right)
$$

Parameter inilah yang digunakan dalam eksperimen.

\section{PERANCANGAN MODEL}

\subsection{Perencanaan Hardware [3]}

Keperluan hardware meliputi : modul ASCII pada PLC sebagai alat kontrol utama, modul Analog Input pada PLC dan hardware pendukung (Digital to Analog Converter, Amplifier) untuk mengkondisikan sinyal antara PLC dan plant. Hanya unit ASCII yang akan dijelaskan dengan detail pada paper ini.

\subsubsection{Unit ASCII [5]}

Unit ASCII adalah unit pelengkap cerdas dari PLC C200H OMRON yang membuat system kontrol berbasis PLC lebih fleksibel dan berkemampuan tinggi. Unit ASCII ini dapat digunakan untuk memonitor sistem, memproses data, membuat laporan dan mengerjakan tugas - tugas lainnya. Pemrograman pada ASCII Unit dikerjakan dengan BASIC, sebagai pengganti ladder diagram, sehingga lebih cocok untuk memproses data analog.

- $\quad$ Konfigurasi

Berikut ini konfigurasi sistem dengan modul ASCII. 


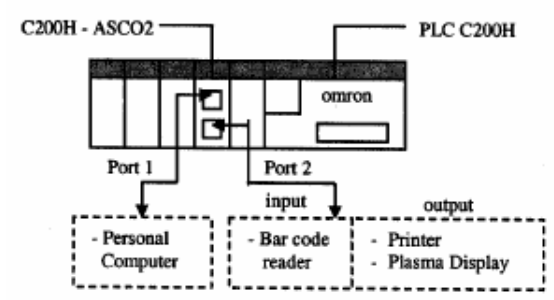

Gambar 2. Konfigurasi Sistem dengan ModulASCII

- $\quad$ Komunikasi

Untuk menggunakan Unit ASCII yang berhubungan dengan PLC, diperlukan program untuk Unit ASCII yang ditulis dalam BASIC. Perintah pertukaran data harus disertakan ke dalam program PLC kecuali jika pernyataan perintah yang digunakan telah menggunakan petunjuk daerah memori yang spesifik (misal : PC READ “@...”, PC WRITE “@...”). Perintah tersebut harus menentukan jumlah word yang akan ditransfer, base address, dan daerah memori yang spesifik. Hal ini bisa dilakukan dengan menggunakan instruksi PC MOV.

Ada 2 cara Unit ASCII dapat berkomunikasi dengan PLC. Pada metoda pertama, PLC mengontrol timing transfer data antara 2 alat ini. ASCII Unit "meminta" akses ke daerah memori data PLC dengan menggunakan statement PC READ, PC WRITE, PC GET, atau PC PUT, dan kemudian menunggu PLC merespon dengan menyalakan read atau write flag.

Pada metoda yang ke dua, tidak ada kode pertukaran data khusus dari PLC yang diperlukan untuk mengkomunikasikan 2 alat ini. Jika parameter penunjuk daerah memori telah ditentukan dengan statement PC READ atau PC WRITE, Unit ASCII dapat langsung mengakses daerah memori PLC yang telah ditentukan. Gambar - gambar berikut ini mengilustrasikan hubungan antara program di PLC dan program di ASCII Unit.

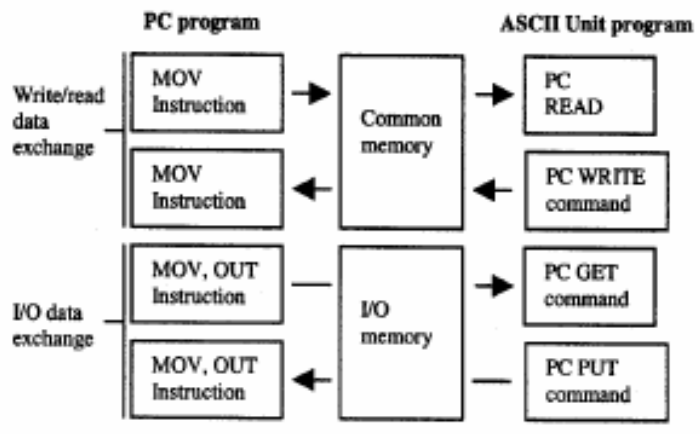

Gambar 3. Hubungan antara program di PLC dan program di unit ASCII

Program BASIC untuk ASCII Unit harus ditulis pada PC yang dihubungkan dengan port 1 ASCII Unit melalui RS 232-C. Sebuah program dapat ditransfer ke TEKNOIN, Vol. 10, No. 4, Desember 2005, 283-293 
ASCII Unit dari PC atau alat penyimpan lain dengan perintah LOAD. LOAD juga digunakan untuk mentransfer program dari EEPROM ke RAM dalam Unit ASCII.

Sebaliknya, program dapat ditransfer dari RAM ke EEPROM dari ASCII Unit atau ke PC yang terhubung dengan perintah SAVE. Selain itu, program juga dapat ditransfer dengan mudah dengan software bawaan dari OMRON yaitu SYSMATE ASCII. ASCII Unit dihubungkan ke alat peripheral melalui dua RS-232C interface. Konektor $\mathrm{dB} 9$ digunakan untuk kedua port. Berikut ini susunan rangkaian untuk upload program.

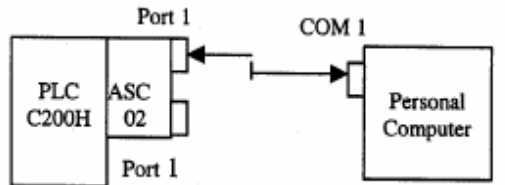

Gambar 4. Rangkaian hardware untuk upload output program

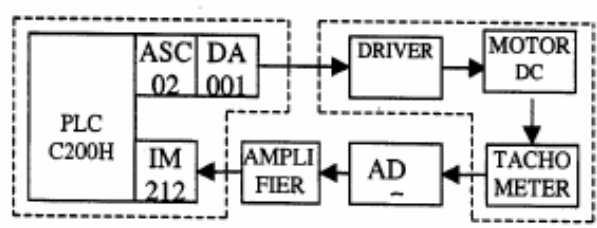

Gambar 5. Rangkaian hardware untuk running program

\subsubsection{Rangkaian Lengkap Hardware}

Gambar 6 menunjukkan rangkaian lengkap PLC, plant, dan hardware pendukung lainnya yang dipergunakan dalam percobaan

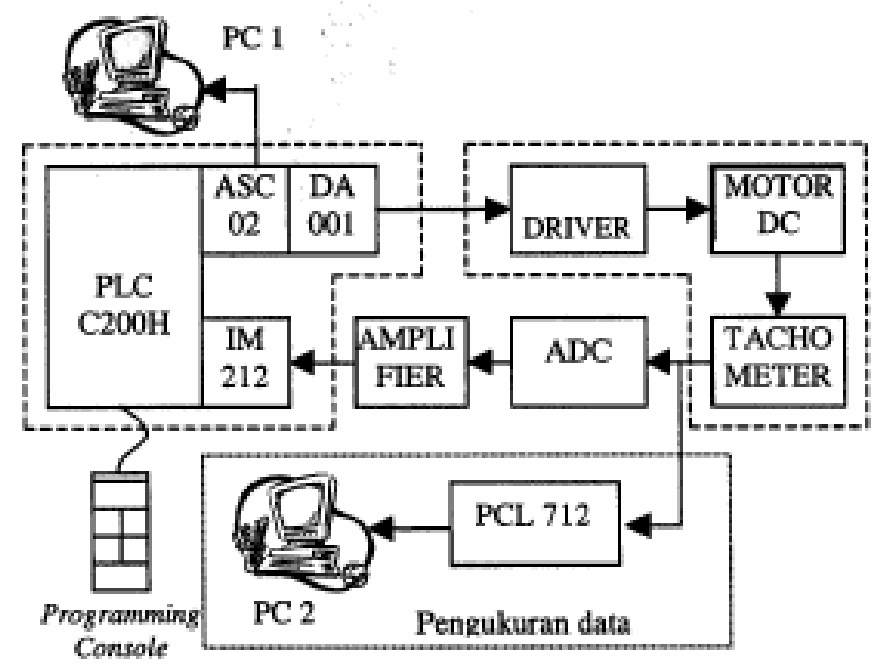

Gambar 6. Rangkaian hardware 


\subsection{Perencanaan Software}

Selain masalah hardware, software yang bekerja sebagai "jantung" dari sistem sangat penting untuk direncanakan dengan tepat. Di antaranya ialah algoritma untuk transfer data dan implementasi kontroler digital.

\subsubsection{Algoritma Transfer Data [5]}

Data dari plant (motor DC) berupa tegangan yang dihasilkan oleh tachometer. Tegangan analog antara $0-5 \mathrm{~V}$ tersebut dimasukkan ke dalam ADC 8 bit dan akan diubah menjadi 8 digit bilangan biner yang merepresentasikan nilai tegangan analog tersebut berdasarkan nilai - nilai biner dari MSB (Most Significant Bit) sampai LSB (Least Significant Bit). Nilai keluaran ADC sebesar 0 - $5 \mathrm{~V}$ tersebut akan dikuatkan sebesar 4 kali karena level logic pada Input Module PLC adalah 0 - $24 \mathrm{~V}$, yang akan dianggap sebagai data input PLC.

Data input PLC ini dengan ladder tertentu akan dikirimkan kepada modul ASCII, dimana modul ini akan menerima data dengan program BASIC tertentu. Di dalam modul ASCII, data akan diolah sesuai keinginan programmer (dalam hal ini dimasukkan dalam program kontroler PID), kemudian hasil akhirnya akan dikirimkan lagi ke PLC dengan program BASIC tertentu. PLC akan menerima data dengan ladder tertentu juga. Sedangkan data dari PLC berupa data digital 8 bit yang akan diubah ke dalam bentuk tegangan analog melalui modul analog output (DA 001).

\subsubsection{Implementasi Algoritma Kontroler Digital[6]}

Selain itu implementasi kontroler PID secara digital juga harus diterapkan dengan benar dan teliti. Modul ASCII pada PLC akan digunakan sebagai kontroler PID. Aspek-aspek implementasi kontroler dalam program (digital) ialah sebagai berikut:

- $\quad$ Persamaan kontroler PID digital :

$$
m_{n}=K_{c}\left[T_{d} \frac{\left(e_{n}-e_{n-1}\right)}{\Delta t}+e_{n}+\frac{1}{T_{i}} \sum_{k=0}^{n} e_{k} \cdot \Delta t\right]
$$

- $\quad$ Penggunaan Sampling time: 0,2 detik.

- Perlu adanya penambahan konstanta MV yang mewakili nilai dari manipulated variable saat steady state supaya tidak terjadi keadaan sinyal kontrol $=0$ saat error $=0$. Besar MV $=3,5 \mathrm{~V}$.

- Mengatasi integral windup atau integral saturation dengan membatasi besarnya komponen integral atau sinyal kontrol yaitu antara 2,5-8 V.

- $\quad$ Dengan memasukkan nilai- nilai parameter kontroler PID berdasar metoda tuning : Direct Sinthesys yang telah dijelaskan, berikut hasil yang didapatkan. $K_{p}=1,826 ; \mathrm{T}_{\mathrm{i}}=1,632 ; \mathrm{T}_{\mathrm{d}}=0,028$ 


\section{HASIL PENGUKURAN DAN ANALISA}

\subsection{Identifikasi Sistem [7]}

Identifikasi proses atau sistem dilakukan berdasarkan data percobaan/eksperimen dengan mengukur sinyal masukan dan keluaran. Identifikasi yang dilakukan berikut adalah metoda identifikasi Strejc yang merupakan salah satu contoh dari metoda eksperimental. Dari perhitungan yang dilakukan berikut model matematika yang didapatkan:

$$
G(s)=\frac{0,847}{(1,604 s+1)(0,056 s+1)}
$$

Dari perhitungan dengan Matlab untuk membandingkan hasil simulasi dan respon sebenarnya, didapatkan norm error yang cukup kecil antara keduanya yaitu sebesar : 4,8608.

\subsection{Kriteria Performansi [8]}

Dengan mengacu pada pengertian yang diberikan Ogata [8], berikut ini kriteria performansi dari plant yang digunakan:

- $\quad$ Berada dalam pita akurasi 5\% (lebih atau kurang dari 5\% set point). Dalam besaran tegangan : 3,8 V - 4,2 V.

- $\quad$ Error steady state kurang dari 5\% dari set point (agar berkorelasi dengan syarat akurasi). Dalam besaran tegangan kurang dari 4,2 V.

- $\quad$ Rise time maksimal $1 \mathrm{~s}$.

- $\quad$ Setting time maksimal $2 \mathrm{~s}$

- Maximum overshoot sebesar 5\% dari set point. Dalam besaran tegangan : maksimal 4,2 V.

\subsection{Hasil dan Analisa Pengujian Sistem}

Pengukuran data dilakukan dengan menyusun rangkaian seperti pada gambar 6, dan merekam hasilnya.

\subsubsection{Simulasi dan Percobaan Close Loop Test I Perubahan Set Point}

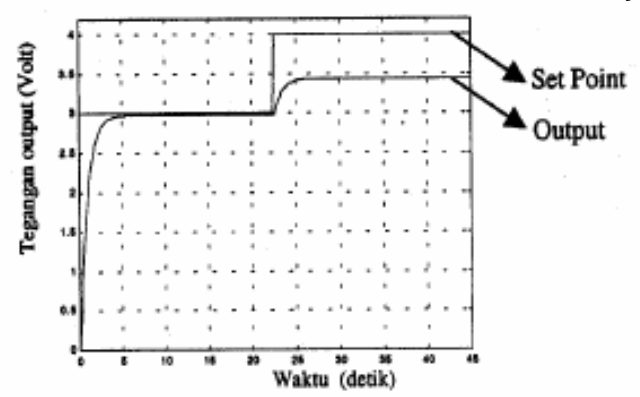

Gambar 7. Simulasi close loop test I untuk plant tanpa kontroler

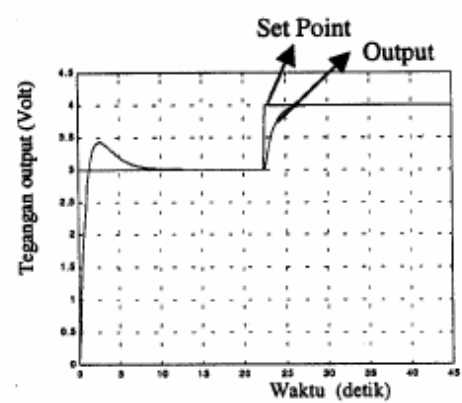

Gambar 8. Simulasi close loop test I untuk plant dengan kontroler PID metoda tuning Direct Sinthesys 
Eksperimen pertama yang dilakukan ialah dengan memberikan perubahan set point pada plant yang tealah running dan steady. Berikut ini gambar hasil simulasi dengan MATLAB dari eksperimen tersebut untuk plant tanpa kontroler. Hasil simulasi plant tanpa kontroler pada gambar 7, dan hasil simulasi plant dengan kontroler PID-Direct Synthesis pada gambar 8.

\subsubsection{Simulasi dan Percobaan Close Loop Test II Input Disturbances}

Close loop test ini dilakukan dengan memberikan tegangan input sebesar $4 \mathrm{~V}$ sehingga motor akan bergerak dan mencapai keadaan steady, kemudian akan diberikan gangguan (disturbances) berupa rem magnetik. Dengan percobaan ini akan dilihat bagaimana aksi kontroler dalam menangani adanya gangguan ini. Hasil simulasi plant tanpa kontroler dan hasil simulasi plant dengan kontroler PIDDirect Synthesis adalah sebagai berikut :

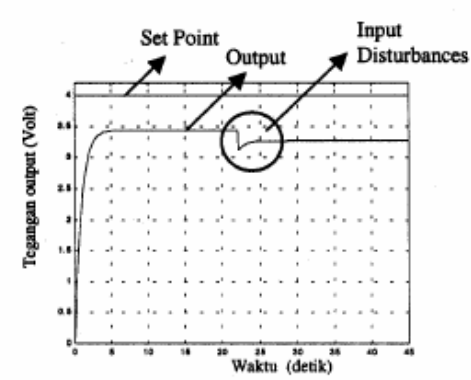

Gambar 11. Simulasi close loop test II untuk plant tanpa kontroler

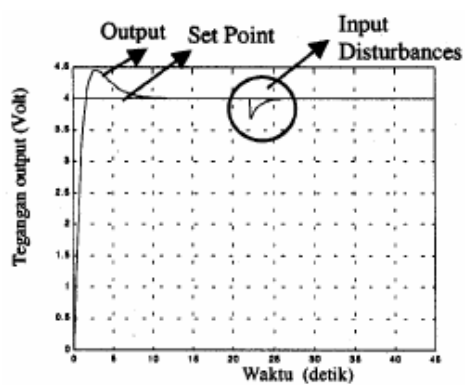

Gambar 12. Simulasi close loop test II untuk plant dengan kontroler PID metoda tuning Direct Synthesis

Hasil percobaan sebenarnya dari plant tanpa kontroler dan plant dengan kontroler PID-Direct Synthesis :

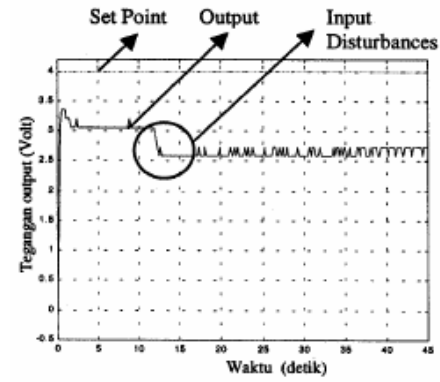

Gambar 13. Close loop test II untuk plant tanpa kontroler

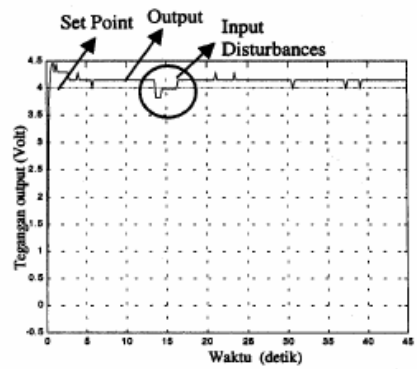

Gambar 14. Close loop test II untuk plant dengan kontroler PID metoda tuning Direct Synthesis

Berikut ini hasil pencatatan kriteria performansi masing-masing sistem. Dari tabel 2 nampak bahwa penambahan kontroler PID metoda tuning Direct Synthesis memberikan perbaikan waktu kembali pada plant. 
Tabel 2. Hasil pengamatan waktu kembali pada close loop test II

\begin{tabular}{|c|c|c|}
\hline NO & METODA & $\begin{array}{c}\text { Waktu Kembali } \\
\text { (detik) }\end{array}$ \\
\hline 1 & Tanpa kontroler (simulasi) & - \\
\hline 2 & Dengan kontroler PID (simulasi) & 2,88 \\
\hline 3 & Tanpa kontroler (percobaan) & - \\
\hline 4 & Dengan kontroler PID (percobaan) & 2,88 \\
\hline
\end{tabular}

\section{SIMPULAN DAN SARAN}

\subsection{Simpulan}

Dari pembahasan dalam penelitian ini dapat disimpulkan bahwa :

a. Implementasi kontroler PID pada modul ASCII-PLC C200H untuk mengatur kecepatan motor DC dapat dilakukan.

b. Implementasi metoda tuning Direct Sinthesys pada kontroler PID memberikan criteria performansi plant yang cukup baik (memberi akurasi, error steady state : 0,144 detik, maximum overshoot: 0 , rise time : 0,36 detik, dan settling time : 0,54 detik) dan kemampuan untuk kembali mencapai set point saat diberikan disturbance.

\subsection{Saran}

Saran - saran untuk mengembangkan penelitian ini ialah:

a. Implementasi self-tuning PID dengan fuzzy logic untuk peningkatan performa control dari kontroler PID.

b. Pemilihan jenis dan karakteristik plant yang tepat agar berbagai pengembangan dalam eksperimen dapat dilakukan.

\section{PUSTAKA}

[1] Willis, M. J. (1999) Proportional-Integral-Derivative Control, http://lorien.ncl. ac.uk/ ming/pid/pid.pdf

[2] H. Sugimoto and S. Tamai. (1985) Secondary resistance identification of an induction motor applied model reference adaptive system and its charecteristics, in Proc. IEEE-IAS Annu. Meeting, , pp. 613-620

[3] Anonim. (1988) Sysmac Programmable Controller C200H Operation Manual, OMRON

[4] L. Zhen and L. Xu. (1995) A mutual MRAS identification scheme for position sensorless field orientation control of induction motors, in Proc. IEEE-IAS Annu. Meeting, , pp. 159-165

[5] T. Nouguchi, S. Kondo, and I. Takahashi. (1997) Field-oriented control of an induction motor with robust on-line tuning of its parameters, IEEE Tran. Ind. Applicat., vol. 33, pp. 35-42, Jan./Feb

[6] R. Marino, S. Peresada, and P. Tomei. (1999) Global adaptive output feedback control of induction motors with uncertain rotor resistance, IEEE Trans. Automat. Contr., vol. 44, pp. 967-983, May 
[7] T. Matsuo and T. A. Lipo. (1985) A rotor parameter identification scheme for vector controlled induction motor drives, IEEE Trans. Ind. Appilcat., vol. 21, pp. 624-632, May/June

[8] L. C. Zai and T. A. Lipo (1987) An extended kalman filter approach in rotor time constant measurement in PWM induction motor drives, in Proc. IEEE-IAS Annu. Meeting, pp. 177-183

[9] Ogunnaike, B.A., dan Ray, W.H. (1994) Process Dynamics, Modelling and Control, Oxford University Press . New York, USA

[10] Smith, C.A., dan Corripio, A.B. (1997) Principles And Practice of Automatic Process Control , John Wiley and Sons Inc . USA

[11] Anonim. (1988) Sysmac C200H Analog I/O Units Operation Guide, OMRON 